ISSN: 1641-4713; e-ISSN: 2081-1160

DOI: https://doi.org/10.36551/2081-1160.2021.28.141-160

\title{
Espacios de represión y sobrevivientes del terrorismo de Estado en Argentina: Notas a partir de los juicios realizados entre 2006 y 2018
}

\author{
Spaces of repression and Survivors of State Terrorism in Argentina. \\ Notes from the judgments carried out between 2006 and 2018
}

\author{
Julio Lisandro Cañón Voirin \\ Universidad de Oviedo \\ ORCID iD: https://orcid.org/0000-0001-7590-5064 \\ E-mail: juliolisandro.canon@gmail.com
}

Recepción: 22.04.2021

Aprobación: 20.12.2021

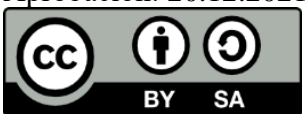

Resumen: Desde 2005 hasta el presente, los juicios por Crímenes de lesa humanidad habidos en Argentina entre 1976 y 1983, generaron una masa de fuentes documentales de origen judicial, testimonial y textual poco trabajada, aún, por el campo historiográfico. El presente trabajo, como parte de una investigación en curso, resulta del relevamiento de doscientas causas judiciales que, cumplimentadas con otras fuentes, nos permiten ensayar una reconstrucción de los complejos represivos. Estos espacios, posteriormente convertidos en prueba judicial, son lugares de memoria y terreno de disputas por los sentidos y las narrativas sobre los pasados traumáticos. Aquí nos interesa plantear y desarrollar la relación entre cada espacio de represión y las memorias de los sobrevivientes de cada uno de ellos.

Palabras clave: terrorismo de estado, sobrevivientes, memorias, juicios, represión

\begin{abstract}
From 2005 to the present, the judgments for Crimes against humanity that took place in Argentina between 1976 and 1983, generated a mass of documentary sources of judicial, testimonial and textual origin, little worked on, even by the historiographic field. This work, as part of an ongoing investigation, results from the survey of two hundred judicial cases that, completed with other sources, allow us to try a reconstruction of the repressive complexes. These spaces, later converted into judicial evidence, are places of memory and terrain of disputes over the senses and narratives about traumatic pasts. Here we are interested in raising and developing the relationship between each space of repression and the memories of the survivors of each one of them.
\end{abstract}

Keywords: state terrorism, survivors, memories, judgment, repression 


\section{PRIMERAS PALABRAS}

Desde la segunda mitad del siglo XX, el mundo occidental conoció una creciente preocupación por la memoria (LaCapra, 2009). Los discursos sobre remembranzas y memoria se instalaron en la agenda política, cultural e historiográfica. La historia social dilató los márgenes de sus estudios, abriéndose a debates postergados por décadas. De este modo, la discusión sobre problemas recurrentes en las sociedades contemporáneas encontró nuevos espacios. En Argentina, ese fenómeno se manifestó de formas particulares y adquirió modalidades específicas.

El terrorismo de Estado en Argentina -1976-1983- constituyó, por su crueldad y magnitud, un escenario histórico sin precedentes. Dejó huellas imborrables y forjó los contornos en torno al problema de la historia, la memoria y el olvido. El largo camino, casi 30 años, que desembocó en el proceso de juzgamiento por crímenes de lesa humanidad -iniciado en 2005- está atravesado por diversos planos de dicha problemática ${ }^{1}$. En ese sentido, el campo de las ciencias sociales ha realizado contribuciones diversas para reflexionar sobre el pasado reciente y traumático de Argentina (Feierstein, 2012).

Hay estudios sobre los juicios por Crímenes de Estado, cuyas obras principales están estructuradas desde el paradigma de la justicia transicional y del derecho internacional humanitario (Nino, 1997, 2012). Al mismo tiempo, existe

\footnotetext{
${ }^{1}$ El retorno a la legalidad constitucional en 1983 estuvo marcado por el inicio de las investigaciones judiciales y por la creación de la Comisión Nacional Sobre la Desaparición de Personas. Esta investigó, mediante la recepción de denuncias y pruebas, las desapariciones de personas ocurridas entre 1976 y 1983. Entre abril y diciembre de 1985, se desarrolló el llamado Juicio a las Juntas. La Cámara Federal de la Capital en lo Criminal y Correccional, nótese que no se trató de tribunales especiales, sino de la justicia ordinaria, tuvo a su cargo el enjuiciamiento de las Juntas militares que se ocuparon el poder durante el terrorismo de Estado. En 1986, La Ley de Punto Final (23.492) estableció la paralización de los procesos judiciales contra los responsables del delito de desaparición forzada de personas. Un año después, la Ley de Obediencia Debida (23.521) estableció que los delitos cometidos por los miembros de las Fuerzas Armadas no eran punibles, por haber actuado en virtud de la denominada obediencia debida. No tardarían en llegar los indultos entre 1989 y 1990. Para 1998, la Corte Suprema de Justicia reconoció el derecho a la verdad, con lo que comenzaron los Juicios por la Verdad, sin posibilidad de condenar penalmente, tenían como objetivo conocer la suerte de los desaparecidos. Así, hasta que, en 2003, la entonces diputada de Izquierda Unida, Patricia Walsh, presentó en la Cámara baja un proyecto para anular las leyes de Punto Final y Obediencia Debida. El proyecto con media sanción de Diputados pasó al Senado, que lo convirtió en ley en agosto de 2003. Dos años después, en 2005, un fallo de la Corte Suprema de Justicia de la Nación Argentina permitió reiniciar los enjuiciamientos interrumpidos (Véase: Corte Suprema de Justicia de la Nación. Capital Federal, Ciudad Autónoma de Buenos Aires, 14 de junio de 2005. 1767. XXXVIII. Recurso de Hecho. Simón, Julio Héctor y otros s/privación ilegítima de la libertad, etc. -causa $N^{o}$ 17.768-. Disponible en: http://www.saij.gob.ar/corte-suprema-justicia-nacion-federal-ciudad-autonoma-buenos-aires-simon-julio-hector-otros-privacion-ilegitima-libertad-etc-poblete-causa-17768-fa05000115-2005-06-14/123456789-511-0005-0ots-eupmocsollaf).
} 
una veta ricamente explorada que, basada en el registro oral, se ha centrado en las madres y familiares de las víctimas de los Crímenes de Estado (Bousquet, 1981; Catela, 2001). Por otra parte, una zona de estudios muy prolífica atendió a la objetivación de la memoria, analizando la transformación de centros de exterminio en museos, los señalamientos de estos y sus expresiones estéticas (Gugliemucci, 2013). Finalmente, los ensayos de reflexión política, donde la tensión conflictiva entre historia y memoria es sometida a escrutinio crítico, han desnudado una parte de la trama que teje el vínculo entre memoria y reconstitución histórica del pasado. Los debates suscitados se prologan en congresos y en un dilatado boom editorial (Franco \& Levin, 2007; Sarlo, 2005). Todo ello, sin duda, ha tenido una enorme importancia, incluso, más allá del ámbito académico.

En los juicios, más allá de lo estrictamente coyuntural, aparecen aspectos políticos, económicos y sociales del terrorismo de Estado y, cómo no, sus autores materiales e intelectuales. Pero también están las vivencias traumáticas. Y, con ellas, teniendo en cuenta que los juicios son orales y públicos, sustentados en un plano testimonial de indudable peso probatorio, el rol de los testimonios. En ese sentido, los juicios han generado una masa de fuentes documentales de origen judicial, testimonial y textual poco trabajada, aún, por el campo historiográfico. Por otra parte, los juicios resultan de una larga sedimentación que opera en varios planos. Primero, los juicios son la expresión de un momento específico de las relaciones dominación-resistencia propias del campo político. En ese sentido, materializan dos momentos de oportunidad política: uno en 1983 y, otro, en 2003. Segundo, en la predisposición social de aceptar e interiorizar imaginarios en concordancia con regímenes democráticos, expresados en lemas como Nunca Más (Crenzel, 2008; Feierstein, 2012). Tercero, en la transformación de los sobrevivientes en testigos de la memoria y la puesta en consideración por parte de la sociedad de su testimonio biográfico. Llegados a este punto, es necesaria una puntualización: los juicios potencian las representaciones nemónicas y las visiones políticas que en ellos se disputan, pero no las originan.

De todo el conjunto de cuestiones hasta aquí enunciadas surgen interrogantes muy amplios: ¿cómo elaboran los grupos sociales y los individuos versiones sobre sus pasados quebrados?; ¿cuáles son los efectos sociales de dichas elaboraciones? Sin desplazar el eje, pero dándole mayor énfasis a los recuerdos de las heridas, de la muerte, de las desapariciones, ¿hay una memoria social específica del dolor? Y en ese caso, ¿cuáles son sus características? Preguntas oportunas, pero que, sin embargo, exceden los propósitos de este estudio. El objeto de este trabajo está determinado por el proceso en que los sobrevivientes asumen el rol de testi- 
gos. Y, a partir de él es desde donde se formulan las preguntas que orientan esta investigación: ¿cómo podemos caracterizar a los sobrevivientes que pasaron por la experiencia traumática de ser secuestrados, torturados y reducidos a procesos de encierro o concentración durante el terrorismo de Estado?; ¿qué características tuvo el proceso de asociación en que los sobrevivientes se transformaron en agentes de memoria y en actores políticos en el marco de los juicios?

A partir de esas preguntas orientadoras, atendiendo a los actores históricos involucrados, deseamos abordar la compleja relación entre espacios de represión, sobrevivientes y memorias. Primero, identificaremos y definiremos los lugares donde se practicó el terror de Estado que, posteriormente, pudieron convertirse en espacios de memoria. Segundo, estableceremos diferentes tipologías de sobrevivientes y la expresión en sus memorias traumáticas. Finalmente, analizaremos las relaciones, nexos y formas en que estos sobrevivientes se transforman en grupos nemónicos-políticos durante los juicios.

Antes de continuar avanzando, es preciso señalar que este estudio se inscribe y, al mismo tiempo, se desprende de un proyecto de investigación que lo contiene y lo trasciende ${ }^{2}$. En ese proyecto de investigación estamos analizando al terrorismo de Estado como modalidad especifica de Estado capitalista de excepción. A nuestro entender, la estructuración progresiva del terrorismo de Estado en Argentina durante la última dictadura, acaecida entre 1976 y 1983, dio lugar a una forma extrema de Estado: el Estado terrorista (Cañón, 2018; Román, 2018). Dentro de ese proceso, realizamos un recorte específico para observar las modificaciones en las estructuras objetivas del Estado, donde su rama represiva se convirtió en dominante. Esas modificaciones son verificables en el trabajo empírico. Así, tras relevar 200 causas judiciales de Crímenes de Estado, que se cumplimentan con otras fuentes, obtuvimos los datos que nos permiten observar la realización de las transformaciones objetivas en las estructuras del Estado ${ }^{3}$. Es decir, su ingreso en la realidad, en este caso específico, se materializó a través de lo que denominamos complejos represivos.

\footnotetext{
2 Proyecto de Investigación: "Los regímenes de terrorismo de Estado y el Estado terrorista en América del sur (1971-1990)". 2019-PG053. Consellería de Cultura, Educación e Ordenación Universitaria. Xunta de Galicia.

${ }^{3} \mathrm{La}$ construcción de la base de datos que trabajamos en el presente texto se halla disponible en: https://www.cij.gov.ar/lesa-humanidad.html Al mismo tiempo, nos hemos valido del "Informe de Investigación sobre Víctimas de Desaparición Forzada y Asesinato, por el accionar represivo del Estado y centros clandestinos de detención y otros lugares de reclusión clandestina", elaborado por el Registro Unificado de Víctimas del Terrorismo de Estado. Disponible en: https://www.argentina.gob.ar/sitiosdememoria/ruvte/informe
} 
Estos últimos - no cabe duda-constituyen un abismo de horror. Un horror perpetrado por el Estado que, a través de una violencia racionalmente dirigida, actuó sobre los sujetos-objetos de su violencia, a los que no definió por lo que eran, sino por lo que hacían. De aquí, nuestro supuesto general: la identidad dominante de los sobrevivientes es política. En este aspecto, sin que exista una representación colectiva homogénea, aparece con gran vehemencia un aspecto clave de la resistencia. En los juicios, reaparece la otredad que pretendió anihilar radicalmente por el terrorismo de Estado. Esa otredad que se quiso eliminar y aniquilar, aquella que sirvió para identificar y estigmatizar a los sujetos-objetos de la violencia estatal: el subversivo ${ }^{4}$. Es decir, los grupos sujetos-objetos de la violencia, fueron el activo de las izquierdas reformistas o revolucionarias, ya fueran estas parlamentaristas, clasistas, insurgentes o armadas. Mayoritariamente, los desaparecidos eran jóvenes de clase trabajadora y de clase media.

FigURA 1. DESAPARECIDOS POR PROFESIÓN

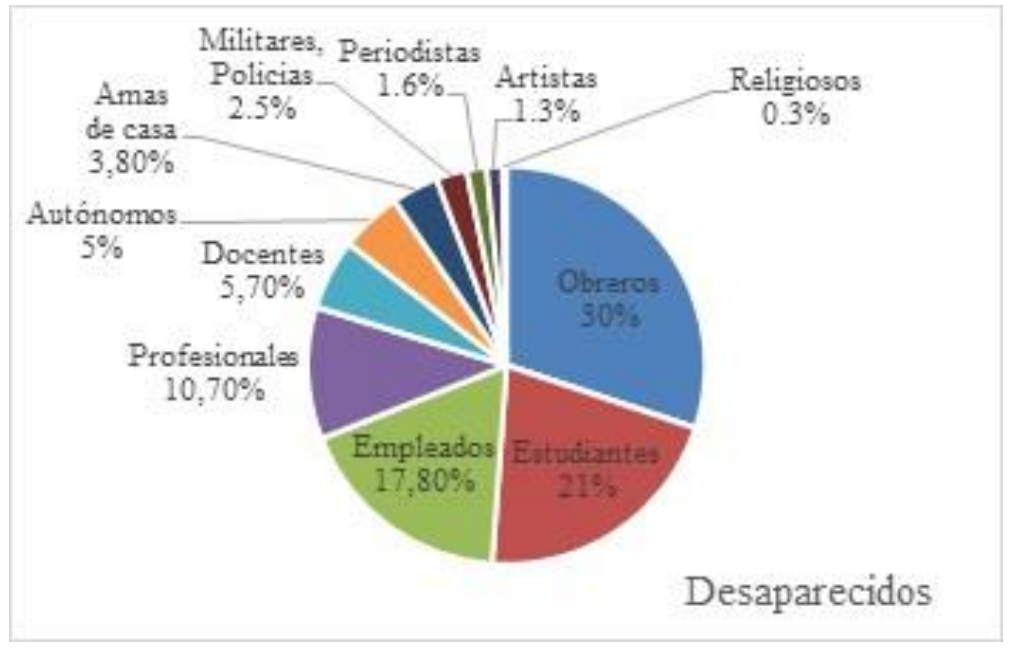

Fuente: Elaboración propia en base a Secretaría de Derechos Humanos de la Nación, 2015a, 2015b.

\footnotetext{
${ }^{4}$ Para que la aniquilación o desaparición de un grupo pueda ser practicada, es necesaria su definición previa, y esa definición debe ser en términos de deshumanización. No solo debe ser considerado indeseable y carente de las condiciones para pertenecer a la comunidad nacional, sino que se debe desposeer a sus miembros de la condición humana. Las potenciales víctimas deben ser consideradas inferiores en su estatuto de ser, pensar y obrar, expulsándolas hacia la inhumanidad, cosificándolas. La configuración de ese grupo, subversivo, partió de su no reconocimiento social, salvo en su rol admitido y socialmente construido de agresor (Cañón, 2017).
} 
FigURA 2. DeSAPARECIDOS POR EDADES

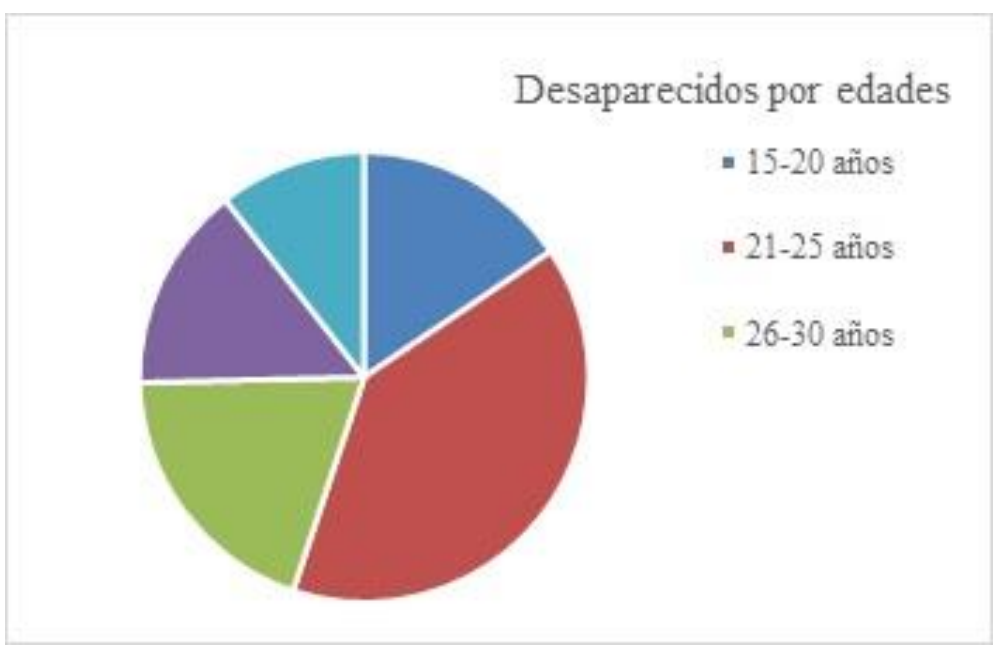

Fuente: Elaboración propia en base a Secretaría de Derechos Humanos de la Nación, 2015a, 2015b.

Lo anterior gana en comprensión cuando se observa al terrorismo de Estado en el marco de las relaciones dialécticas en que se produjo. Esto es, un momento histórico en que la revolución y el socialismo no eran un proyecto utópico, y en el que las expresiones de la izquierda radical y revolucionaria fueron madurando tanto dentro los grupos sociopolíticos más dinámicos como entre multitudes de jóvenes de clase media que se hallaban ligados a esas visiones por vínculos políticos. La respuesta a este ascenso social fue el terrorismo de Estado, materializado en este caso en los complejos represivos.

\section{ESPACIOS DE REPRESIÓN: LOS COMPLEJOS REPRESIVOS}

Si algo distingue al Estado moderno hegemónico y, al mismo tiempo, lo diferencia de los tipos de Estado que le precedieron, es haber conseguido el monopolio de la violencia. Esa potestad le permite contar con todos los recursos posibles de la legalidad para implementar medidas de represión, bajo el control de las instituciones de coerción. Sin embargo, la realidad ha mostrado que los Estados pueden liberarse de las limitaciones correlativas al Estado de derecho y aplicar una violencia racionalmente dirigida para eliminar, destruir o cuando menos debilitar a determinados grupos humanos. Esto, que supone una alteración fundamental en los principios del Estado de derecho, es lo que sucedió en Argentina, entre 1976 y 1983, cuando el aparato represivo de Estado, incluso incorpo- 
rando nuevas ramas, se hizo dominante (Cañón \& Román, 2019). En efecto, a la actividad contemplada en el marco jurídico del Estado de derecho, la dictadura incorporó una actividad paralela y secreta, al margen de toda legalidad formal, con el crimen selectivo y masivo como método fundamental.

La metódica frialdad con la que se planificaron los complejos represivos -centros de exterminio, centros de alta y de baja intensidad represiva-, instalados por toda la geografía argentina y la existencia de un accionar masivo, deliberado y sistemático -secuestro, tortura, asesinato y desaparición-, que anuló el deber estatal de velar por la integridad de todas las personas, dan cuenta de las decisiones político-militares que configuraron un aparato represivo extremo; esto es, terrorista. El régimen dictatorial dividió al país en diferentes zonas, subzonas y áreas. En las principales guarniciones militares, comisarías y edificios de las Fuerzas Armadas se establecieron campos de concentración, con salas de tortura y espacios para alojar a los cientos de secuestrados que, todos los días, ingresaban a la feroz maquinaria represiva. Para 1976, ya están funcionando más de la mitad de los 772 campos que existieron. Se trató de la conformación de un sistema de complejos represivos dirigidos estratégicamente por unidades militares e implantadas en todo el territorio nacional.

La dictadura reconfiguró el espacio político nacional. Así, las jurisdicciones históricas, como la ciudad capital; las provincias y sus capitales; sus partidos interiores y ciudades intermedias; sus pueblos, sus espacios rurales y sus campos yermos quedaron subordinados a un proceso de zonificación de guerra interna con que los dictadores organizaron una nueva territorialidad ${ }^{5}$. De este modo, se instituyó un nuevo sistema de jurisdicciones dividido en zonas, subzonas y áreas. Las subzonas fueron dispositivos intermedios entre los mandos militares estratégicos y los territorios operacionales concretos. Estos últimos eran las áreas, espacios de represión reducidos: urbanos, suburbanos o rurales. Todos ellos cuales tuvieron su propia jurisdicción, articulados jerárquicamente en las unidades de comando. Zonas, subzonas y áreas configuraron la territorialidad donde se implantaron los complejos represivos que, si bien, presentan características generales, es posible distinguir rasgos regionales y locales. El proceso de zonificación se llevó a cabo a partir de un análisis detallado de las características demográficas, sociales, políticas y culturales de la zona de guerra, tal y como fue

\footnotetext{
${ }^{5}$ Poder Ejecutivo Nacional, "Ley 16970, Bases Jurídicas, orgánicas y funcionales para la preparación y ejecución de la Defensa Nacional”, Boletín Oficial de la República Argentina, número 21043, 10 10-1966. "Directiva del Consejo de Defensa N 1/75 (Lucha contra la Subversión)", 28-10-1975. Secretaría de Derechos Humanos, Documentos del Estado terrorista, Ministerio de Justicia y Derechos Humanos de la Nación, Buenos Aires, 2012.
} 
denominada a partir de ese momento. En ese sentido, la zonificación fue un dispositivo que buscó totalizar el espacio nacional, controlar y aislar a los grupos sociopolíticos más dinámicos del conjunto de la población para de esta manera encerrarlos y ejercer sobre ellos el proceso de aniquilación.

En lo que respecta a los complejos represivos, los centros de exterminio, a diferencia de la homogeneidad del Läger alemán, no fueron resultado de nuevas construcciones. Se instalaron en edificios, estaciones, galpones, sótanos, escuelas, campamentos, casas, caballerizas y las más diversas instalaciones militares o de Fuerzas de Seguridad que, aunque estuvieran derruidas o abandonadas, ofrecieran condiciones adecuadas para las necesidades previstas. Todos los centros tuvieron su sede de mando, su administración burocrática y clasificadora. Cada uno de ellos, delimitó espacios de tormentos, estableció áreas de concentración, marcó las zonas de muerte y desarrolló formas de desaparición de cadáveres. Los centros de exterminio materializan un poder que organiza su propio espacio, destruye la alteridad y establece relaciones sociales de sometimiento conforme a las nuevas relaciones de fuerza. En ese sentido, los centros de exterminio fueron ramas específicas del Estado para destruir una parte sustancial de la vida social. Para ello necesitó del secreto, por una parte, para aislarse, alienarse del mundo exterior, del mundo social; pero, por otra, necesitó ensimismarse, construir una realidad propia, un cosmos en el que pudiera circular, con la máxima libertad posible, el poder omnímodo de sus agentes. Paradójicamente, ese poder oculto liberó una potencia que se transmitió por relaciones porosas hacia el conjunto social, cristalizándolo, inmovilizándolo.

En el esquema de los complejos represivos, siguiendo a Román (2020), es posible identificar otros dos tipos de centros: a) de alta intensidad represiva; y b) de baja intensidad represiva. Ambos, funcionaron en instalaciones que no fueron modificadas - en general, comisarías de las policías federal o provinciales. En los de alta intensidad, los secuestrados permanecieron durante periodos cortos o discontinuos, siendo sometidos a tormentos por grupos de tareas o personal policial. Posteriormente, fueron trasladados a los centros de exterminio, derivados al sistema penal o puestos en libertad vigilada. Estas unidades de represión también cumplieron roles operativos y de logística, quedando vinculadas jerárquicamente a los mandos de las áreas ${ }^{6}$. Los de baja intensidad, comparten las características de los anteriores, excepto en que los secuestrados no fueron sometidos a tormentos.

\footnotetext{
${ }^{6}$ Un ejemplo de estos centros en Poder Judicial. Tribunal Oral federal № 1. Entre Ríos. Paraná. Sentencia. Expediente N FPA 33056208/2006/TO1. "Causa Mazzaferri”, 2017.
} 
Finalmente, al circuito de los complejos quedaron integrados el Servicio Penitenciario y los hospitales militares y civiles. El primero, responsable de incorporar a los secuestrados cuando estos pasaban a ser presos legales. Los segundos, bien, para atender a los heridos graves fruto de los secuestros y torturas o, bien, para asistir a las secuestradas parturientas (Román, 2020).

\section{SOBREVIVIENTES Y MEMORIAS}

Para distinguir procesos que se oponen a la memoria oficial, Michael Pollak elaboró la noción de memoria subterránea (Pollak, 1989). En ésta, según Pollak, pervive por infinitas redes y relaciones sociales lo no dicho, el olvido y el silencio. Ahora bien, partiendo de lo anterior, creemos que es posible diferenciar distintos tipos de memorias subterráneas. Ello es, además, necesario, ya que, si bien la memoria de los sobrevivientes es considerada como el testimonio jurídico determinante en las sedes judiciales, existen otros tipos de testimonios. Estos, en parte estimulados por los procesos judiciales, expresan discursos e interpretaciones conformes a los relatos de los grupos políticos contemporáneos y a los hechos relatados por los sobrevivientes (García, 2016). Dicha superposición puede llevarnos a conclusiones que deforman el problema tratado. De este modo, presentamos tres tipos de memorias de sobrevivientes que experimentaron diferentes formas de poder exterminador: los sobrevivientes de encierro, los sobrevivientes de tormentos y los sobrevivientes de centros de exterminio ${ }^{7}$.

Los sobrevivientes de encierro son aquellos que, en Argentina, se conoce como expresos políticos ${ }^{8}$. Se trata, por una parte, de detenidos por Fuerzas de Seguridad en 1975 y derivados al Servicio Penitenciario; por otra, de personas que, a partir de 1976, fueron secuestradas por los grupos de tareas ${ }^{9}$, pero que, por diferentes razones, fueron trasladadas al Servicio Penitenciario. En ambos casos, fueron puestos a disposición del Poder Ejecutivo, adoptando el status jurídico de preso político (Garaño \& Pertot, 2007). Estos sobrevivientes presentan una característica fundamental: articularon una comunidad de prisioneros. "En este sentido

\footnotetext{
${ }^{7}$ Postergamos, por razones de espacio y para no dispersar el núcleo de esta investigación, el problema del trauma y memoria de los familiares directos de las víctimas. Por otra parte, existe una muy dilatada cantidad de trabajos en torno de estos grupos (Catela, 2001).

8 Poder Ejecutivo Nacional, "Ley 24043, Beneficios Indemnizaciones", Boletín Oficial de la República Argentina, número 27296, 02-01-1992.

${ }^{9}$ Según la estructuración represiva, planificada secretamente por las FF.AA., la detención legal fue reemplazada por el secuestro, siendo los Equipos Especiales, más conocidos como patotas o grupos de tareas los encargados de practicarlos.
} 
creo que uno de los temas más prolíficos es la incomunicación, como objetivo de los milicos y su contrapartida, el nuestro, de mantenernos comunicados a toda costa. Allí después podemos encajar lo de la solidaridad, nuestras respuestas al régimen represivo" (Obra Colectiva Testimonial, 2003, p. 25) Este extracto de una memoria colectiva, redactada por algo más de un centenar de presos políticos, rescata la comunicación como resistencia a la dureza del régimen carcelario de la dictadura.

La comunicación, entonces, se transforma en el eje central de la estructura nemónica. Una práctica del lenguaje, donde muchos de sus léxicos y gestualidades fueron constituidos por los propios sobrevivientes como formas de resistencia. Tampoco es menor la importancia de los cursos y tareas de educación política organizadas por ellos mismos, en los propios sitios de reclusión. Asimismo, el aislamiento social al que fueron sometidos en las cárceles operó como una forma más de estrechar los vínculos de solidaridad. Desde luego, que estos sobrevivientes soportaron durísimas condiciones de encierro, incluso muchos de ellos fueron asesinados. Pero, el hecho de que fueran militantes políticos y de alguna manera pudieran seguir desarrollando, de forma limitada, algunas prácticas políticas, condicionó la magnitud de los procesos de disociación y de desubjetivización. Las largas horas de hastío, propias del encierro, fueron mitigadas por una actividad que identificaba a los sobrevivientes ${ }^{10}$.

Dentro de la tipología propuesta, hay un segundo grupo: sobrevivientes de centros de alta y baja intensidad represiva. Este grupo presenta dos características principales: lo reducido en cuanto a número y la edad que tenían al momento de ser secuestrados, de entre 13 y 18 años ${ }^{11}$. En general, las prácticas políticas de estos sobrevivientes estaban centradas en la actividad gremial de los centros de estudiantes, en el movimiento por el medio boleto estudiantil y otros intereses propios de este grupo de edad. Precoces militantes políticos, pero con escasa trayectoria en grupos vinculados a partidos políticos de las diferentes izquierdas. Estos sobrevivientes fueron sometidos a los mismos tormentos que los del grupo anterior. Mayormente, fueron secuestrados en el mismo operativo que los sobrevivientes de encierro, pero a diferencia del grupo anterior no fueron, salvo muy contadas excepciones, trasladados al Servicio Penitenciario. La política que la dictadura se dio para estos sobrevivientes fue su desaparición o su legalización bajo la figura de libertad vigilada. Esto es, una variante de prisión domiciliaria o dentro de los límites de la subzona, tal el léxico militar, al que el sobreviviente pertenecía.

\footnotetext{
${ }^{10}$ Para los procesos de disociación y desubjetivización: Kersner \& Madariaga, 2002; Kordon, 1995. ${ }^{11}$ Sobre el problema de los estudiantes secundarios desaparecidos y secuestrados existen muy pocas aportaciones analíticas (Seoane \& Ruiz, 2003; Cañón, 2012).
} 
Parte de estos sobrevivientes emigraron al exterior o migraron al interior del país. Las condiciones sociales de los sobrevivientes por tormentos fueron determinadas por un silencio y un olvido profundo, agudizado por persecuciones imaginarias o reales por parte de los perpetradores. De esta forma, a diferencia del grupo anterior, estos sobrevivientes no pudieron comunicarse, reconocerse y mucho menos constituirse en tanto comunidad. Por otra parte, los padecimientos sufridos no pudieron hablarse, ni elaborarse por las condiciones de silencio y olvido. Así, sobrecargaron las condiciones de opresión social, ya sea en la diáspora migratoria o en el gueto local ${ }^{12}$.

El último grupo que hemos identificado es el de los sobrevivientes de los centros de exterminio ${ }^{13}$. Aquí, no hubo comunidad de prisioneros y tan siquiera diásporas o guetos ${ }^{14}$. Las condiciones de secuestro en los centros de exterminio fue una práctica de poder básicamente disociativa y desubjetivante. De ahí que en un número muy frecuente sufrieran lo que el psicoanálisis denominó memoria traumática (Kordon, 1995). El trauma o herida, sobrepasa al sujeto haciendo que reviva el trauma sin que el sobreviviente pueda tener el control de la frecuencia e intensidad de este evento psíquico porque rompe los esquemas mentales e impide la asimilación de la experiencia en la estructura psíquica. El suceso traumático no es una simple memoria más del pasado que ha sido procesada normalmente, sino que reside en un ámbito particular al resto de las memorias, pues, desencadena síntomas de analepsis, que altera la secuencia cronológica del tiempo y el espacio, conectando momentos distintos y trasladando la acción al pasado ${ }^{15}$. Nora Strejilevich, poetisa, escritora, académica, pero fundamentalmente sobreviviente del Centro de Exterminio el "Vesubio" lo expone de la siguiente manera:

\footnotetext{
${ }^{12}$ Para el estudio de estos sobrevivientes nos hemos basado en: "Causa Número 1960/10 "Harguindeguy, Albano Eduardo y Otros S/Inf. Art. 151 y otros del Código Penal" y sus acumuladas la Número 1.991/10 caratulada: "Díaz Bessone, Ramón Genaro y Otros S/Inf. Art. 141 y otros del Código Penal" y la Número 2138/11 caratulada: "Valentino, Juan Miguel y Otros S/Inf. Art. 141 y otros del Código Penal", Tribunal Oral Federal número 1, Paraná, Entre Ríos, 27-12-2012. Poder Judicial. Tribunal Oral federal $\mathrm{N}^{\circ} 1$. Entre Ríos. Paraná. Sentencia. Expediente $\mathrm{N}^{\circ}$ FPA 33056208/2006/TO1. "Causa Mazzaferri”, 2017.

${ }^{13}$ Para el estudio y seguimiento de estos sobrevivientes hemos consultado las fuentes consignadas en el Apéndice número 1. Se trata de 16 sentencias dictadas entre 2006 y 2018. Hemos procedido a una selección de entre las 221 sentencias, atendiendo a un criterio de representatividad territorial y densidad poblacional. Al mismo tiempo, tuvimos en consideración la cantidad de sobrevivientes que prestaron declaración en cada causa.

${ }^{14}$ Para una interpretación diferente, se sugiere la lectura de Bacci, C., Capurro Robles, M., Oberti, A., \& Skura, S. (2012). Y nadie quería saber.... Relatos sobre violencia contra las mujeres en el terrorismo de Estado en Argentina. Buenos Aires: Memoria Abierta.

${ }^{15}$ Para el concepto de analepsis: Caruth, 1996.
} 
quien sale de un campo siente la necesidad de testimoniar para sobrevivir, dar testimonio es una forma de confrontar el horror otorgándole sentido no al pasado sino al presente. Los testigos tienen que encontrar las palabras justas para dar cuenta de un universo que parece irreal, pero a la vez es más nítido que cualquier presente, tienen que hallar las formas adecuadas para unir su ser dividido (...) Sólo mediante este esfuerzo pueden reubicarse en el tiempo y en el espacio de la sociedad, logrando que el pasado quede como pasado en lugar de permanecer como un presente persecutorio. Esta labor, si bien se plantea como requisito para recuperar la propia identidad, sirve de hecho para impulsar el acto de contar. En el caso de nuestras dictaduras, la identidad plasmada por la fuerza utópica setentista fue derrotada, no puede recuperarse. Lo que se recupera es cierta dignidad después de la degradación sistemática (Strejilevich, 2005, pp.17-18).

En consecuencia, este tipo de memoria tiene elementos singulares y ha precisado de diferentes elaboraciones del trauma que le subyace para hacerse palabra en el testimonio. Sea esto por intervenciones terapéuticas grupales o individuales o por expresarse en una narrativa escrita. El testimonio no se puede desarrollar si no es desde un tiempo presente, como dice Strajilevich, la memoria del terror es una experiencia permanente entre los sobrevivientes, pues, intenta establecer puentes entre el pasado traumático y el presente que habla o escribe de ese trauma. De ahí la necesidad secuencial del detalle y la metáfora.

\section{JUICIOS, SOBREVIVIENTES Y MEMORIA}

Los juicios del siglo XX, a diferencia de los del siglo pasado ${ }^{16}$, incorporan en sus sentencias diferentes tipos judiciales: crímenes contra la humanidad, crímenes de lesa humanidad, crímenes en marco del genocidio argentino y genocidio (Ministerio Público Fiscal, 2019). Esto responde a que los juicios se insertan en relaciones de fuerza y dependiendo de la disposición relativa de éstas avanzaron en la búsqueda de verdad y justicia o se sumergieron en el olvido.

Los juicios del siglo XX, desde 2006 a hoy, arrojan bastos niveles de información, así como de territorialización y de enfoque jurídico relevante. Si en 2006 solo había dos sentencias, para 2019 hay 221. El número de acusados por Crímenes de Estado pasó de 922, en 2007, a 3.161 en 2019; de ellos, 901 han sido condenados y 142 absueltos. Por otra parte, el número de víctimas también se ha incrementado notablemente. En la ciudad de Mar del Plata, por ejemplo, en 1985 había 226 desapariciones denunciadas ante la CONADEP; sin embargo, según

\footnotetext{
${ }^{16}$ En el Juicio a las Juntas, los delitos imputados fueron homicidio agravado por alevosía, privación ilegítima de la libertad agravada por amenazas y violencias, tormentos seguidos de muerte y robo. El resultado del proceso judicial fueron las condenas a reclusión perpetua para Videla, a prisión perpetua para Massera, a 17 años para Viola, a ocho años para Lambruschini y a cuatro años y medio para Agosti. Los acusados Omar Graffigna, Leopoldo Galtieri, Jorge Isaac Anaya y Basilio Lami Dozo no fueron condenados por no haberse podido probar los delitos que se les imputaban.
} 
nuestras propias estimaciones, al día de la fecha, se hallan denunciados en los siete juicios con sentencia o en proceso de instrucción 437 desaparecidos, más un número aún indeterminado de desaparecidos-aparecidos -sobrevivientes- $\mathrm{y}$ expresos políticos (CONADEP, 1984) ${ }^{17}$.

Los juicios se consustanciaron con relación a los espacios de represión centros de exterminio, centros de alta o baja intensidad represiva o unidades de encierro del Servicio Penitenciario-, por lo que hubo juicios prácticamente en todo el país. Los juicios constan de dos fases: una de instrucción y otra de elevación a juicio oral y público. Las formas de buscar la verdad siguieron los términos del derecho procesal argentino (Abal, 2008; Zaffaroni, 1996). Así, los primeros investigados por los tribunales de instrucción fueron los propios sobrevivientes, ahora convertidos en denunciantes o querellantes. Los sobrevivientes, transformados en testigos, antes de llegar al juicio oral, son citados en varias oportunidades a declarar bajo juramento y pena de falsear la verdad, ya que su testimonio es el elemento probatorio determinante.

Este proceder se relaciona con los mecanismos de prueba legalmente admitidos por la legislación; es decir, la inspección judicial. Así, el juez o el tribunal toman contacto directo y personal con los rastros y efectos materiales que el hecho delictivo hubiera dejado. La característica principal de esta modalidad probatoria está dada en la inmediación entre el objeto verificable y el

\footnotetext{
${ }^{17}$ Estimaciones propias en base a las diez causas judiciales radicadas en el Tribunal Oral Federal de Mar del Plata, a saber: “Causa Número 93017807/2007/. “Argüello, Adriano - Mápero, Aldo Carlos s/Privación ilegal libertad personal, imposición de tortura (Art. 144 Ter. Inc. 1), imposición de tortura agravada (Art. 144 Ter. Inc. 2), homicidio agravado con ensañamiento alevosía y homicidio agravado por el concurso de dos o más personas", 2-12-2014. "Causa Número 2086 y su acumulada Número 2277 "Molina, Gregorio Rafael s/ privación ilegal de la libertad, etc.", 9-06-2010. "Causa Número 2286, y su acumulada Número 2283. "Malugani Juan Carlos, Pertusio Roberto s/Av. Homicidio Calificado" y su acumulada 5033 "Regine Luis y Segura Margarita s/ denuncia", 21-12-2010. "Causa Número 237/09 "Unidad de Asistencia en causas por violaciones a los derechos humanos durante el terrorismo de Estado s/ Denuncia", 18-02-2011. "Causa № 2473 "Secretaría de Derechos Humanos de la Provincia de Buenos Aires s/denuncia" (Causa "Moreno")", 16-03-2012. "Causas Número 2278 y su acumulada 2300 y 2301 (y sus acumuladas 2325 y 2345), Número 2380 y Número 2405 "Caffarello, Nicolás s/ Delito contra Derechos de Gentes" (y causas acumuladas Nros. 2300 "Caffarello", 2301 "Bicarelli”, 2380 "La Cueva” y 2325 "Comisaría IV")", 1-10-2012. "Causa Número 2333 y sus acumuladas 2334 y 2335 (Arrillaga II) Malugani, Juan Carlos, Pertusio, Roberto s/ Av. Homicidio Calificado (y su acumulada Número 5113 "Frigerio s/ Denuncia" - elevaciones de los imputados 6 y 8 - y causa Número 5180) Base Naval II”, 15-02-2013. “Causa Número 93306153/2005 “Leites, Horacio Rubén - Grosse, Walter Jorge - Ferreyra, Omar Antonio - Verdura, Ignacio Aníbal s/ infracción arts. 142 y 144 CP (Lesa Humanidad)", 29-12-2014. "Causa Número 4447 "Malugani Juan Carlos y otros s/ homicidio calificado" Pertusio, Roberto Luis y Otros s/Privación ilegal libertad agravada (Art. 142 Inc. 1), Imposición de tortura agravada (Art. 144 Ter. Inc. 2), Homicidio agravado por el concurso de dos o más personas y asociación ilícita”, 25-02-2016. “Causa Número 33013793 “Averiguación delito de acción pública (CNU)", 20-12-2016.
} 
juzgador, pues este concurre sin intermediario alguno a la percepción de las circunstancias que desea verificar. Durante la primera fase, la de instrucción, la inspección judicial adquiere mayor relevancia. En primer lugar, porque el instructor tiene el deber de adoptar todas las medidas y de realizar todas las diligencias tendientes a la averiguación de los hechos. Los objetos para examinar serán las cosas, personas o lugares, relacionados directa o indirectamente con el suceso delictivo. El juez debe dejar constancia explícita y material de todo lo verificado, sin añadir apreciaciones personales. Estos elementos así constatados servirán eventualmente de indicadores o comprobadores de un hecho principal por sí mismo o como indicio de otros hechos, de modo que su utilidad resulte indirecta como eficacia probatoria. Todo lo que sea materia de examen y verificación en la inspección queda registrado en el expediente judicial: los testimonios, el relevamiento de planos y croquis, las muestras fotográficas, filmaciones o grabaciones y los informes periciales.

En ese marco, los testimonios se inscriben en el discurso jurídico y la memoria se fragmenta en pos de la verdad judicial. Los jueces interrogan a los testigos buscando indicios, estableciendo una secuencia temporal, delimitando los hechos y lugares. No existe el testigo, hay grupos de testigos que exponen lo que el juez pregunta. Así, el sistema judicial potencia la apelación al detalle, a la descripción minuciosa de los lugares, de los actos y de las personas -muy particularmente el reconocimiento de los perpetradores-. Si bien, cada grupo de testigos es heterogéneo respecto de la experiencia de concentración o encierro, un número muy importante de ellos ya tenía una dilatada trayectoria en las organizaciones de derechos humanos y actuaron como sujetos de la propia acción judicial como querellantes.

Los juicios, en su segunda etapa, cuando son elevados a oral y público se abren a una pluralidad de actores más allá del ámbito judicial, tales como la prensa, el movimiento de derechos humanos, los partidos políticos y demás actores sociales y culturales. Pero, además, se abre una disputa política, no exenta de violencia de parte de los perpetradores sobre los testigos en forma de amenazas, atentados, amedrentamientos e, incluso, desapariciones ${ }^{18}$. La fase oral da la oportunidad política para que los testigos expongan no solo la experiencia traumática sino su biografía anterior. Enuncian desde un yo, en varios casos desde un nosotros, que pretende recuperar su dignidad presente, pero que parte de una referen-

\footnotetext{
${ }^{18}$ En este aspecto el caso paradigmático fue la desaparición de Julio López, 18 de septiembre de 2006, luego de haber aportado importantes testimonios en la causa Etchecolazt. Hoy en día permanece desaparecido. Al respecto, véase: Natalia Arenas, Julio López: el desaparecido perpetuo. Diario Popular, 25-07-2013.
} 
cia a su biografía política anterior a los procesos de encierro, tormentos o concentración. Entonces, los grupos de testigos dan cuenta de memorias políticas y, al mismo tiempo, dan cuenta de un continente ético de resistir al poder de la última dictadura, fuera esto, en el encierro o en los centros de concentración. Finalmente, parece haber un discurso común a todos los sobrevivientes/testigos: la unidad de vivir para dar testimonio del horror.

Un momento crucial es el reconocimiento, por parte de los testigos-víctimas, de los lugares donde funcionaron los centros de exterminio, represión o encierro, ya que la experiencia de volver al lugar del terror recrea el trauma. Un agravante para las víctimas es que el avistamiento se hace al menos dos veces, durante el juicio de instrucción y durante el juicio oral y público. Otro perjuicio sin duda grave es que los sobrevivientes se encuentran, frecuentemente, con personal que tuvo tareas de guardia durante las etapas de concentración o encierro. Esta es una experiencia de shock, pero que contradictoriamente intensificó la necesidad de proyectar la memoria señalizando estos espacios centrales al terrorismo de Estado.

Figura 3. Sitios y Espacios de Memoria en Argentina, 2007 a 2015

\begin{tabular}{|c|c|c|}
\hline $\begin{array}{c}\text { Cantidad de lugares } \\
\text { de represión }\end{array}$ & $\begin{array}{c}\text { Cantidad de lugares } \\
\text { señalizados }\end{array}$ & $\begin{array}{c}\text { Cantidad de lugares } \\
\text { de Espacio de Memoria }\end{array}$ \\
\hline 762 & 101 & 24 \\
\hline
\end{tabular}

Fuente: Elaboración propia en base a Secretaría de Derechos Humanos de la Nación, 2015 b.

En el cuadro anterior puede leerse una cantidad importante de lugares señalizados, entre los años 2007 a 2014, promulgados por la Ley de Sitios, en que se evidencia una intervención estatal muy activa en ese aspecto. Sin embargo, fue una actividad básicamente de los sobrevivientes y de las organizaciones de derechos humanos que acompañaron los juicios ${ }^{19}$. Los espacios de la Memoria tienen una historia pretérita más densa, vinculadas a iniciativas museográficas, vinculada al movimiento de derechos humanos y a las políticas de Estado (Gugliemucci, 2013, pp. 239-283). En cualquier caso, la señalización y los espacios de la Memoria buscan que esta no solo opere en el plano judicial, sino también en el plano social, en que la reconstrucción del funcionamiento de los mecanismos del terrorismo de Estado se haga presente en el espacio público y urbano, ineludible para no olvidar el destino de los desaparecidos y conocer y transmitir la experiencia terrorista.

${ }^{19}$ Poder ejecutivo de la Nación, "Ley 26691, Decláranse Sitios de Memoria del Terrorismo de Estado, a los lugares que funcionaron como centros clandestinos de represión ilegal", Boletín Oficial de la República Argentina, número 32202, 29-07-2011. 


\section{A LA MEMORIA CUANDO LA LLAMAN, VIENE}

Con la reapertura de las investigaciones judiciales por los crímenes del terrorismo de Estado, lenta pero inexorablemente, los responsables de delitos aberrantes comenzaron a ser puestos en el banquillo de los acusados. Hoy en día, el proceso de juzgamiento de Crímenes de Estado tiene unos datos muy concretos. En total existen 611 causas. De las cuales, 221 ya cuentan con sentencia, 104 han sido elevadas a juicio, 14 se hallan actualmente en juicio, y 244 se encuentran en fase de instrucción. Dentro de esas 611 causas, han sido investigadas 3.161 personas. De las cuales, 901 han sido condenadas, 142 absueltas, 663 están actualmente procesadas, 178 declaradas con falta de mérito, 85 sobreseídas, 33 están en fase indagatoria, 560 son actualmente imputadas, hay 34 prófugas, y 565 han fallecido.

FiguRA 4. CAUSAS POR CRÍMENES DE ESTADO SEGÚN ESTADO PROCESAL

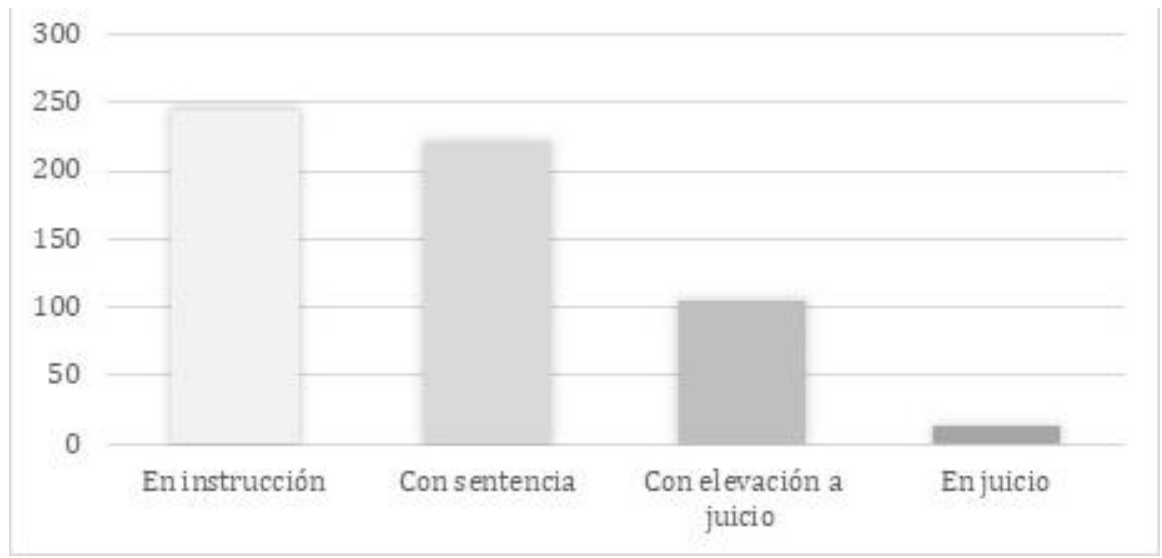

Fuente: Elaboración propia en base a Ministerio Público Fiscal, 2019.

Estos datos nos hablan de una realidad muy concreta. En un mundo regido por la impunidad, los juicios en Argentina hablan de una profunda conciencia. Con sus luces y sus sombras, con sus limitaciones y sus aciertos, los juicios marcan un camino irreversible de cambios sustanciales. La búsqueda de la verdad para saber qué pasó rechaza al olvido. El olvido ignora que el derecho a la justicia es un Derecho Humano del cual depende la seguridad jurídica de las personas. La impunidad es un lastre para que la sociedad asuma lo ocurrido. Ese obstáculo afecta a la democracia, la degrada. Es más, la debilita y abona el surgimiento de nuevas catástrofes. 
Los tribunales de Justicia, sus edificios, se transformaron en espacios de memoria. La memoria irrumpió en los estrados judiciales. Sobrevivientes, familiares y allegados, testimoniaron y relataron los horrores padecidos. Sus palabras, anteriormente desautorizadas, resultaron en una radiografía del terrorismo de Estado. Sus testimonios van construyendo un relato que es a la vez prueba judicial y catarsis personal. Si, por un lado, revivir lo padecido -intentando ponerle palabras a lo indecible- implica una re-victimización; por otro, se produce la restitución de persona después de haber sido un desaparecido.

Los juicios actúan como reparación de la justicia bajo la forma de una condena legal y social a los responsables. Incluso, la trascienden, responden a la necesidad de entender el horror. Los testimonios permiten reconstruir la vida en los campos de concentración. La supresión del nombre, el estar aislados, engrillados, subalimentados, encapuchados, sin acceso a condiciones mínimas sanitarias, con la amenaza de la tortura permanente, nos hablan de un lugar sin límites: la degradación total del ser. Pero, también, nos habla de vencer el miedo, de recuperar la memoria, de reconstruir lo que se vivió prácticamente a ciegas. Nos habla, también, de un cambio. Los secuestrados reelaboraron el concepto mismo de sobreviviente. Ahora, ya no se desnudan para hablar del horror en carne viva. Las historias previas al terrorismo de Estado, la vitalidad de la militancia antes de caer en la obscuridad del centro, reaparecen. La vida afuera y no sólo adentro del centro. Y adentro la que aparece, en muchos casos, son las estrategias de resistencia y no el cuerpo puramente doblegado.

Los grupos de testigos se fueron transformando en nuevos colectivos para constituirse en denunciantes y querellantes según la disposición volitiva de los diferentes grupos, allí donde los Crímenes de Estado se habían manifestado. Esto fue posible porque si bien, cada grupo de testigos es heterogéneo respecto de la experiencia de concentración o encierro, un número muy importante de ellos ya tenía una dilatada trayectoria en las organizaciones de derechos humanos y actuaron como querellantes. Los lazos de solidaridad, aunque devinieran de experiencias disímiles, se forjaban sobre estructuras de sentir análogas. 


\section{BIBLIOGRAFÍA}

Abal, A. (2008). Derecho Procesal. Fundación de Cultura Universitaria.

Bousquet, J.-P. (1981). Las Locas de la Plaza de Mayo. El Cid.

Cañón, L. (2012). Terrorismo de Estado y política educativa: Argentina (1976-1983). Publicacións da Cátedra Juana de Vega.

Cañón, L. (2017). Estado, violencia, violencia de Estado: Una panorámica sobre el continente americano, en la segunda mitad del siglo XX. Revista Universitaria De Historia Militar, (6), 301-312.

Cañón, L. (2018). El Estado Terrorista en América: Una historización sobre su configuración. Confluenze, (10), 4-33.

Cañón, L., \& Román, C. (2019). Terrorismo de Estado en Latinoamérica durante la segunda mitad del siglo XX. Revista Universitaria De Historia Militar, (17), 12-19.

Caruth, C. (1996). Trauma: Explorations in Memory. The Johns Hopkins University Press.

Catela, L. (2001), No habrá flores en la tumba del pasado: La experiencia de reconstrucción del mundo de los familiares de desaparecidos. Al Margen.

CONADEP (1984). Nunca Más: Informe de la Comisión Nacional sobre la Desaparición de Personas. Editorial Universitaria de Buenos Aires.

Crenzel, E. (2008). La história politica del Nunca Más: Las memorias de los desaparecidos en la Argentina. Siglo XXI Editores.

Feierstein, D. (2012). Memorias y representaciones. Fondo de Cultura Económica.

Franco M., \& Levin, F. (2007). Historia reciente: Perspectivas y desafios para un campo en construcción. Paidós.

Garaño, S., \& Pertot, W. (2007). Detenidos-Aparecidos: Presas y presos políticos desde Trelew a la dictadura. Biblos.

García, V. (2016). Testimonio y ficción en la Argentina de la postdictadura: Los relatos del sobreviviente-testigo. Revista chilena de literatura, (93), 73-100. https://doi.org/10.4067/S0718-22952016000200004

Gugliemucci, A. (2013). La consagración de la memoria. Antropofagia.

Kersner, D., \& Madariaga, C. (eds.). (2002). Paisajes del dolor, Senderos de Esperanza: Salud Mental y Derechos Humanos en el Cono Sur. http://www.cintras.org/textos/libros/libropaisajes.pdf

Kordon, D. (1995). La Impunidad: Una perspectiva psicosocial y clínica. Sudamericana.

LaCapra, D. (2009). Historia y Memoria después de Auschwitz. Prometeo.

Ministerio Público Fiscal. (2019). Crímenes de Lesa Humanidad en Argentina: Compendio de Resoluciones de CFCP sobre sentencias definitivas y algunos fallos de la CSJN relevantes. Procuraduría de Crímenes contra la Humanidad, Dirección de Comunicación Institucional. 
Nino, C. (1997). Juicio al mal absoluto. Emecé.

Nino, C. (2012). Ética y derechos humanos. Aestra.

Obra Colectiva Testimonial (2003). Del otro lado de la mirilla: Olvidos y memorias de expresos Políticos de Coronda 1974-1979. El Periscopio.

Pollak, M. (1989). Memoria, olvido y silencio. Revista de Estudios Históricos, (3), 3-15.

Román, C. (2018). Crítica a la concepción inmanentista de la violencia política y perspectivas sobre el terrorismo Estado y el genocidio en la Argentina reciente. Confluenze, (10), 57-79.

Román, C. (2020). Secreto, inteligencia y centros de exterminio en la formación de los complejos represivos en la Argentina del terrorismo de Estado 1975-1983. In L. Cañón (ed.), Estado de excepción y terrorismo de Estado (pp. 459-501). Lago.

Sarlo, B. (2005). Tiempo Pasado: Cultura de la Memoria y Giro Subjetivo. Una discusión. Siglo XXI.

Secretaría de Derechos Humanos de la Nación. (2015a). Anexo I. Listado de víctimas del accionar represivo ilegal del Estado argentino. Victimas de desaparición forzada y asesinato en hechos ocurridos entre 1966 y 1983. http://www.jus.gob.ar/media/3120900/2._anexo_i__listado_de_v_ctimas_de_desap_forzada_y_asesinato__a__k.pdf

Secretaría de Derechos Humanos de la Nación. (2015b). Anexo V. Listado de centros clandestinos de detención y otros lugares de reclusión ilegal del terrorismo de Estado en la Argentina $\begin{array}{llll}\text { entre } & 1974 & y & 1983 .\end{array}$ dia/3122963/6._anexo_v__listado_de_ccd.pdf

Seoane, M., \& Ruiz, H. (2003). La Noche de los Lápices. Contrapunto Sudamericana.

Strejilevich, N. (2005). El arte de no olvidar: Literatura testimonial en Chile, Argentina y Uruguay entre los 80 y los 90 . Catálogos.

Zaffaroni, E. (1996). Derecho Penal. Ediar. 
APÉNDICE 1. LISTADO DE SENTENCIAS SOBREVIVIENTES DE LOS CENTROS DE EXTERMINIO

\begin{tabular}{|c|c|c|c|}
\hline Causa & Lugar & Juzgado & Sentencia \\
\hline $\begin{array}{l}\text { N } 1056 \text { y } 1207 . \\
\text { "Turco Julián" }\end{array}$ & Capital Federal & TOF $N^{\circ}$ 5. Capital & $4 / 8 / 2006$ \\
\hline $\begin{array}{l}\mathrm{N}^{\circ} 2251 \text {. "Etcheco- } \\
\text { latz" }\end{array}$ & La Plata & $\begin{array}{l}\text { TOF No } 1 . \mathrm{La} \\
\text { Plata }\end{array}$ & $19 / 9 / 2006$ \\
\hline $\begin{array}{l}\mathrm{N}^{\circ} \text { 15. "Caggiano } \\
\text { Tedesco" }\end{array}$ & Misiones & $\begin{array}{l}\text { TOF N } 1 . \text { Posa- } \\
\text { das }\end{array}$ & $13 / 7 / 2008$ \\
\hline N 40/M. "Menéndez" & Córdoba & $\begin{array}{l}\text { TOF N } 1 \text {. Cór- } \\
\text { doba }\end{array}$ & $24 / 7 / 2008$ \\
\hline N R-19. "Nicolaides" & Corrientes & $\begin{array}{l}\text { TOF } N^{\circ} 1 \text {. Cor- } \\
\text { rientes }\end{array}$ & $6 / 8 / 2008$ \\
\hline $\mathrm{N}^{\circ}$ V-03. "Vargas" & Tucumán & $\begin{array}{l}\text { TOF No } 1 \text {. Tucu- } \\
\text { mán }\end{array}$ & $28 / 8 / 2008$ \\
\hline $\begin{array}{l}\text { N 1170. "Suárez } \\
\text { Manson" }\end{array}$ & Capital Federal & TOF $N^{\circ}$ 5. Capital & $5 / 11 / 2008$ \\
\hline $\mathrm{N}^{\circ}$ 412. "Reinhol" & Neuquén & $\begin{array}{l}\text { TOF } N^{\circ} 1 . \\
\text { Neuquén }\end{array}$ & $18 / 12 / 2008$ \\
\hline $\mathrm{N}^{\circ}$ 2005. "Riberos" & San Martín & $\begin{array}{l}\text { TOF N }{ }^{\circ} 1 \text {. San } \\
\text { Martín }\end{array}$ & $12 / 8 / 2009$ \\
\hline $\begin{array}{l}\text { № 1120. "Díaz Bes- } \\
\text { sone" }\end{array}$ & Rosario & $\begin{array}{l}\text { TOF N 1. Ro- } \\
\text { sario }\end{array}$ & $16 / 3 / 2012$ \\
\hline $\begin{array}{l}\text { No 2610. "Martínez } \\
\text { Dorr" }\end{array}$ & Santa Fe & $\begin{array}{l}\text { TOF } N^{\circ} 1 \text {. Santa } \\
\mathrm{Fe}\end{array}$ & $26 / 3 / 2012$ \\
\hline Nº 982. "Bayón" & Bahía Blanca. & $\begin{array}{l}\text { TOF N } 1 \text {. Bahía } \\
\text { Blanca }\end{array}$ & $14 / 9 / 2012$ \\
\hline $\mathrm{N}^{\circ}$ 2278. "La Cueva" & Mar del Plata. & $\begin{array}{l}\text { TOF } N^{\circ} 1 . \text { Mar } \\
\text { del Plata }\end{array}$ & $1 / 10 / 2012$ \\
\hline $\begin{array}{l}\mathrm{N}^{\circ} \text { 1960. "Hargu- } \\
\text { indeguy" }\end{array}$ & Entre Ríos & TOF $N^{\circ} 1$. Paraná & $27 / 12 / 2012$ \\
\hline $\mathrm{N}^{\circ}$ 1282. ESMA & Capital Federal & TOF $N^{\circ}$ 5. Capital & $8 / 3 / 2018$ \\
\hline $\begin{array}{l}\mathrm{N}^{\circ} 1282 / 1 . \text { "Vuelos } \\
\text { de la muerte" }\end{array}$ & Capital Federal & TOF $N^{\circ}$ 5. Capital & $8 / 3 / 2018$ \\
\hline
\end{tabular}

